\title{
Comparative Study between Topical Flutamide Alone or Combined with Carboxytherapy in Treatment of Patients with Melasma
}

\author{
ARWA M. HASSAN, M.D.*; GAMAL M. EL-MAGHRABY, M.D.**; \\ GHADA F.R. HASSAN, M.D.* and HEMMAT M. EL-ADAWY, M.Sc.* \\ The Departments of Dermatology \& Venereal Diseases, Faculty of Medicine* and Pharmaceutical Technology, \\ Faculty of Pharmacy**, Tanta University
}

\begin{abstract}
Background: Melasma is one of the most common causes of facial hyperpigmentation which causes cosmetic disfigurement and leads to psychological proplems, although various treatments are available for melasma, it remains a difficult condition to treat.

Aim of Study : To evaluate and compare the efficacy of topical flutamide $1 \%$ alone and in-combination with Carboxytherapy in treatment of patients with melasma.

Patients and Methods: The study included 30 female patients with different types and patterns of melasma. They were divided into two groups, each group included 15 patients: Group A, patients were treated with $1 \%$ flutamide topical gel on the face and group B, patients were treated with $1 \%$ flutamide topical gel on the face and carboxytherapy injection was done in both sides of the face every four weeks for three sessions.
\end{abstract}

Results: Both groups showed highly significant decrease in mMASI score after the treatment in which group B showed better results with $\left(p\right.$-value $\left.=0.048^{*}\right)$ than group A with $(p$ value $\left.=0.007^{*}\right)$.

Conclusion: As new treatment for melasma topical flutamide was effective and safe therapeutic modalities. Carboxytherapy could be effective and safe new treatment modality for melasma as adjuvant treatment with topical flutamide.

Key Words: Topical Flutamide - Carboxytherapy - Melasma.

\section{Introduction}

MELASMA is a common acquired hypermelanosis presents as symmetrically distributed hyperpigmented punctate or macules that occurs on areas exposed to sun. Females in their reproductive age are commonly affected with cheek, upper lip, nose and forehead being the predominant areas of in-

Correspondence to: Dr. Arwa M. Hassan,

The Department of Dermatology \& Venereal Diseases,

Faculty of Medicine, Tanta University volvement. Based on histological and Wood's lamp examination, it can be of epidermal, dermal or mixed type [1]

The major etiological factors of melasma include chronic sun exposure, genetic influences, pregnancy, contraceptives, hormone therapy and drugs [2]

As hormonal role is shown to exist in pathogenesis of melasma, Flutamide as an anti-androgenic agent may theoretically be considered to have an effect in treating melasma. A safe way to assess such an effect would be to use it in its topical form [3].

Carboxytherapy consists of intradermal or subcutaneous injections of medical grade $\mathrm{CO} 2$. It is used for the treatment of dark under-eye circles, stretch-marks, cellulite reduction, and non-surgical fat sculpting on the face and the body. Because of its role in increasing oxygenated blood-flow to the region injected and also it increases collagen formation in the skin, giving it a more youthful appearance [4].

\section{Aim of study:}

To evaluate and compare the efficacy of topical flutamide $1 \%$ alone and in-combination with Carboxytherapy in treatment of patients with melasma.

\section{Patients and Methods}

Thirty Egyptian female patients with melasma were selected among those attending the Outpatient Clinic of Dermatology and Venereology Department, Tanta University Hospitals and Al-Hood ElMarsood Hospital. All participants provided signed informed consent before being included in the 
study. Thirty female patients who were not treated before or stopped treatment at least one month were included in this study. Exclusion criteria were: Patients receiving oral contraceptives, pregnant and nursing women, patients being treated with retinoid through the last 3 weeks, patients with keloid or scar tendency, inflammation, infection, liver disease and patients with hypersensitivity to the components or photosensitivity.

All the patients were subjected to: Complete history taking including: Age, skin type, family history, duration of melasma, history of aggravating and predisposing factors of melasma (UVR exposure, hormonal therapy, pregnancy, cosmetic application, drugs intake and associated diseases e.g. NSAIDs, phototoxic drugs, griseofulvin and phenytoin).

Clinical assessment of melasma: Was performed for each patient. The patients were classified according to the distribution of the lesions into 3 patterns, the centrofacial pattern. The malar pattern. The mandibular pattern [5].Scoring of the patients before, during and after treatment according to (mMASI) score [5] : (mMASI) score $=0.3 \mathrm{~A}(\mathrm{f}) \mathrm{D}$ (f) $+0.3 \mathrm{~A}(\mathrm{~lm}) \mathrm{D}(\mathrm{lm})+0.3 \mathrm{~A}(\mathrm{rm}) \mathrm{D}(\mathrm{rm})+0.1 \mathrm{~A}(\mathrm{c})$ $\mathrm{D}(\mathrm{c})$.

Table (1): Modified melasma area and severity index score grading scales.

\begin{tabular}{ll}
\hline Area (A) value & Darkness (D) grading scale \\
\hline $0=$ No involvement & $0=$ Absent \\
$1=<10 \%$ & $1=$ Slight \\
$2=10-29 \%$ & $2=$ Mild \\
$3=30-49 \%$ & $3=$ Marked \\
$4=50-69 \%$ & $4=$ Maximum \\
$5=70-89 \%$ & \\
$6=90-100 \%$ & \\
\hline
\end{tabular}

Wood's light examination [5]: Was done for each patient and the patients were classified into: Epidermal type, dermal type and mixed type melasma.

\section{Therapeutic regimen:}

Flutamide formulation was prepared by dispersing the drug in propylene glycol. Water was gradually added to the mixer while mixing to form gel like liquid crystals which was packed in suitable container. This dispersion was mixed with tween 80 before addition of oleic acid with mixing. Gel like liquid crystalline preparations containing $1 \%$ w/w flutamide was prepared according to the following formulations. Flutamide liquid crystals:
- Flutamide - - - - - $1 \mathrm{~g}$.

- Tween 80 - - - - - - 20g.

- Oleic acid - - - - 10g.

- Propylene glycol - - - $\quad 10 \mathrm{~g}$.

-Water to - - - - - 100g.

Technique of the procedures: The patients were classified into two groups each group included 15 patients as follow:

- Group A: Patients were treated with $1 \%$ flutamide topical gel on the face at every night after cleaning the face for 12 weeks. Patients were seen regularly every month for clinical assessment.

- Group B: Patients were treated with $1 \%$ flutamide topical gel on the face at every night after cleaning the face. Carboxytherapy injection was done in both sides of the face every 4 weeks for 12 weeks. Before the procedure the skin was cleansed by scrubbing with cotton gauze soaked in ethanol, intradermal injection of $3 \mathrm{cc}$ of $\mathrm{CO}_{2}$, using a $30 \mathrm{G}$ needle. The injection angle was maintained at $<15^{\circ}$ with bevel border up. The flow of $\mathrm{CO}_{2}$ gas was adjusted as Auto mode, depth $3 \mathrm{~mm}$ into the melasma lesion at $2 \mathrm{~cm}$ interval by using sterile syringe, this repeated every 4 weeks for 12 weeks.

Evaluation of the treatment efficacy: Patient's satisfaction score. They were each asked to rate their satisfaction as either extremely satisfied, very satisfied, moderately satisfied or mildly satisfied or as no improvement [6]. Digital image analysis of photographs: Digital image photographs were taken every session used to determine the degree of improvement of the melasma lesion. Measurement of the efficacy of the treatment: Efficacy of the treatment $=(\mathrm{mMASI}$ score before-mMASI score after)/mMASI score before $\mathrm{x} 100$ [7].

Statistical analysis: Data were fed to the computer and analyzed using IBM SPSS software package version 20.0 (v 16; SPSS Inc., Chicago, IL, USA).

\section{Results}

As regard age of the patients in the studied groups, in group A, it ranged from 30.0-45.0 years with a mean of $40.10 \pm 5.00$ years. In group B, it ranged from 30.0-49.0.0 years with a mean of $40.10 \pm 4.52$ years. The duration of melasma in the studied groups, in group A, it ranged from 2.016.0 years with a mean of $8.50 \pm 3.94$ years. In group B, it ranged from 2.0-12.0 years with a mean of $7.11 \pm 3.30$ years. All demographic data of the patients where demonstrated in Table (2). 
Table (2): Distribution of the studied melasma patients according to ultra violet exposure, pregnancy and family history.

\begin{tabular}{lcccccc}
\hline & \multicolumn{2}{c}{$\begin{array}{c}\text { Group A } \\
(\mathrm{n}=15)\end{array}$} & \multicolumn{2}{c}{$\begin{array}{c}\text { Group B } \\
(\mathrm{n}=15)\end{array}$} & & \\
& \multicolumn{2}{c}{$\chi^{2}$} & $p$ \\
\cline { 2 - 5 } & No. & $\%$ & No. & $\%$ & & \\
\hline $\begin{array}{l}\text { Ultra violet: } \\
\text { Negative }\end{array}$ & 6 & 40.0 & 7 & 46.7 & 0.541 & 0.455 \\
$\quad$ Positive & 9 & 60.0 & 8 & 53.3 & & \\
Pregnancy: & & & & & & \\
$\quad$ Negative & 6 & 46.7 & 6 & 40.0 & 0.141 & 0.711 \\
$\quad$ Positive & 9 & 53.3 & 9 & 60.0 & & \\
Family History: & & & & & & \\
$\quad$ Negative & 9 & 60.0 & 7 & 46.7 & $\chi^{2}=$ & 0.456 \\
Positive & 6 & 40.0 & 8 & 53.3 & 0.541 & \\
\hline
\end{tabular}

As regard m MASI score before and after treatment with $1 \%$ Flutamide topical gel on the face. In group $\mathrm{A}$, the mMASI score before treatment ranged from $0.61-6.1$ with a mean of $3.33 \pm 1.91$ and the mMASI score after treatment ranged from 0.31-6.1 with a mean of $2.93 \pm 1.82$, there was a significant decrease in mMASI score after treatment $\left(p\right.$-value $\left.=0.007^{*}\right)$.
In group $\mathrm{B}$, the mMASI score before treatment ranged from 1.20-5.40 with a mean of 3.20 1.28 and the mMASI score after treatment ranged from $0.20-4.50$ with a mean of $1.63 \pm 1.08$, there was a highly significant decrease in mMASI score after treatment $\left(p\right.$-value $\left.=0.001^{*}\right)$. There was a statistically significant difference between group B and group A after treatment in which group B showed better results in the right side with $(p$-value $=$ $0.048 *)$.

As regard patient satisfaction in studied groups, in group A, 1 patient was extremely satisfied $(6.7 \%), 1$ patient was very satisfied $(6.7 \%), 5$ patients were modertely satisfied $(33.3 \%), 6$ patients were mildly satisfied $(40.0 \%)$ and 2 patients were not satisfied (13.3\%). In group B showed the highest satisfaction, 3 patients were extremely satisfied $(20 \%), 7$ patients were very satisfied $(46.7 \%), 4$ patients were modertely satisfied $(26.7 \%)$ and 1 patient was mildly satisfied (6.7\%). There was significant difference between the studied groups as regard the patient satisfaction $(p$ value $\left.=0.017^{*}\right)$ with the best results in group $B$. (Figs. 1,2).

Fig. (1), Group (A):

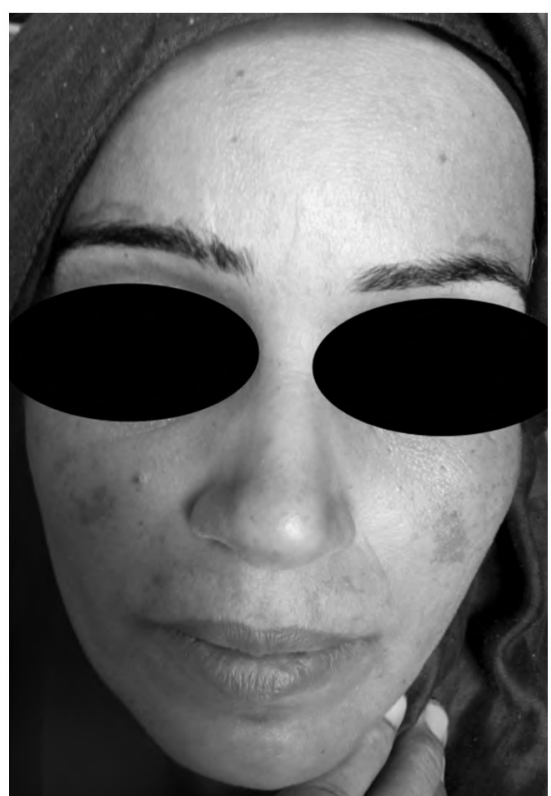

(Before treatment), mMASI score $=6.3$

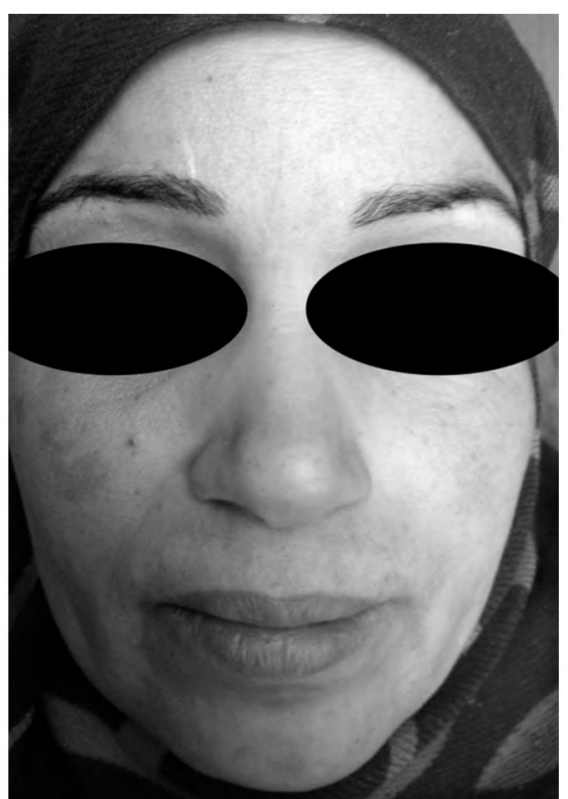

(After treatment), mMASI score $=3.6$ (Very satisfied) 
Fig. (2), Group (B):

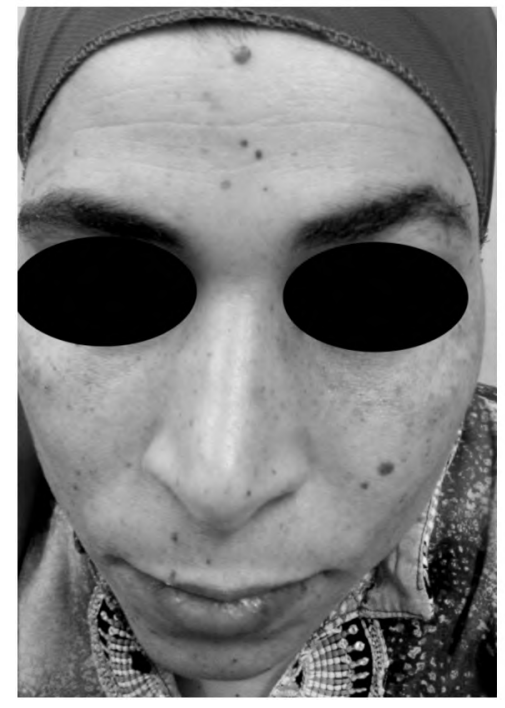

(Before treatment), mMASI score $=3.6$

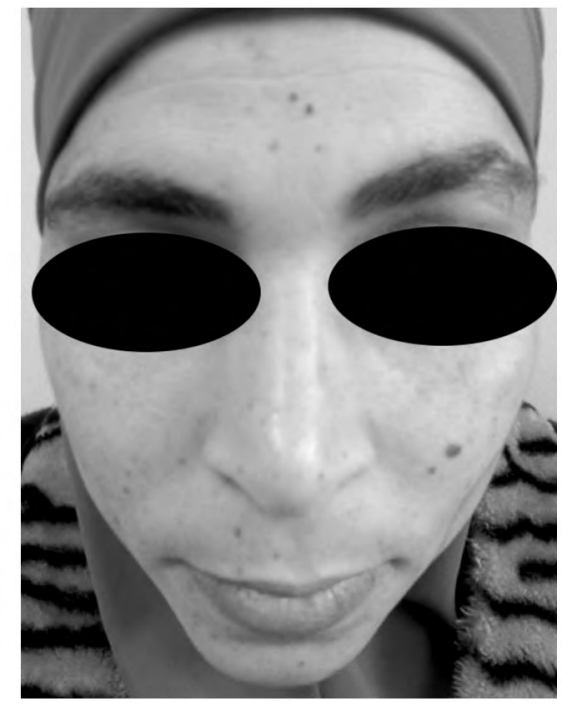

(After treatment), mMASI score $=0.3$

(Extremely satisfied)
As regard correlation between the efficacy of treatment with different parameters between the studied groups, revealed that in group A, there was no statistically significant correlations between the efficacy of treatment and age, family history or duration of melasma with ( $p$-value $=0.332,0.961$, 0.761 ) respectively. In group B, no statistically significant correlations were found between the efficacy of treatment and age, family history and duration of melasma with $(p$-value $=0.880),(p$ value $=0.741)$ and $(p$-value $=0.331)$ respectively.

\section{Discussion}

In our study, as regard the age of the studied patients of melasma, it ranged from 30-49 years with a mean of $40.10 \pm 4.52$ years. Melasma usually appeared in females during reproductive age that using combined estrogen-progesterone contraceptive methods. This was in agreement with PerezBernal, 2000 [8] and Achar and Rathi 2011 [9]

Kang et al., [10] agreed with the current results. He stated that melasma is more common in adult women in childbearing age and the age of onset between 30-55 years.

As regard the duration of melasma in the present study, it ranged from 2-16 years with a mean of $8.60 \pm 3.94$ years. This was in accordance with Ilknur et al., [11]. They found that it ranged from 2-20 years. While these results disagreed with Achar et al., [9] who found the mean duration of melasma was 3.60 years. This was explained as the transient type of melasma disappears within a year of withdrawal of aggravating factor or hormonal stimulus while the long duration of melasma is due to persistent type melasma which maintain long time if the hyperpigmentation is deep, continuous exposure to UVR or any other factors [12].

The current study showed that, As regard the history of pregnancy was the most detected factor in the predisposing factors which was found in 18 patients $(57.0 \%)$. History of UVR exposure was found in 17 patients $(53.3 \%)$. These results were in agreement with Handel et al., [13] as they reported history of pregnancy in (52\%), followed by UVR exposure in (49\%). History of UVR exposure could be explained by socioeconomic standard of the patients as most of them are farmers, poor and not oriented by using sunscreens. Moin et al., [14] disagreed with these results who stated that UVR exposure is a major triggering predisposing factor in development of melasma. These finding disagreed with Hexsel et al., [15] who stated that melasma occur in (10-20\%) of pregnant women. Sarvjot et al., [16] stated that melasma should not be considered a hereditable disorder but affected with other factors as sun light and the use of cosmetics that contribute to the development of melasma. In this study family history was found in 14 patients (46.6\%), Achar et al., [9] they found positive family history in $33.35 \%$ of patients therefore genetic factor could be considered as important predisposing factor in accordance with the current results.

Regarding the treatment with $1 \%$ Flutamide topical gel on the face, there was highly significance 
decrease in mMASI score from the base line to the end of the treatment. In group A, the mMASI score before treatment ranged from 0.61-6. 1with a mean of $3.33 \pm 1.91$ and the mMASI score after treatment ranged from 0.31-6.1 with a mean of 2.93 \pm 1.82 , there was a significant decrease in mMASI score after treatment $(p$-value $=0.007 *)$. In group $\mathrm{B}$, the mMASI score before treatment ranged from 1.20 5.40 with a mean of $3.20 \pm 1.28$ and the mMASI score after treatment ranged from 0.20-4.50 with a mean of $1.63 \pm 1.08$, there was a highly significant difference in mMASI score after treatment ( $p$ value $=0.001 *)$. On evaluation of the patient satisfaction in the present study, in group A, 1 patient was extremely satisfied $(6.7 \%), 1$ patient was very satisfied $(6.7 \%), 5$ patients were moderately satisfied $(33.3 \%), 6$ patients were mildly satisfied $(40.0 \%)$ and 2 patients were not satisfied (13.3\%). In group $B$ showed higher patient satisfaction than group A, 3 patients were extremely satisfied (20\%), 7 patients were very satisfied $(46.7 \%), 4$ patients were moderately satisfied (26.7\%) and 1 patient was mildly satisfied $(6.7 \%)$. There was significant difference between the two groups ( $p$-value $=$ $\left.0.017^{*}\right)$ with the best results in group B. These results were in agreement with Elbuluk et al., [17] who used $1 \%$ flutamide cream daily for three months and they reporetd a significance decrease in mean MASI score. And Adalatkhah et al., [18] who used $1 \%$ flutamide cream and $4 \%$ hydroquinone cream daily for three months and the results of their study confirmed that both the hydroquinone and flutamide creams were effective in treating the melasma. However, flutamide appeared to have higher efficacy than hydroquinone with respect to the patient satisfaction score as well as the MASI scale score.

Flutamide in its topical or oral forms has been used earlier for treatment of acne, hirsutism, and hair loss with promising results in human and animal studies. As regard the role of androgenic disorders in melasma, it is also very hard to understand the exact mechanism of action observed for the effect of flutamide on melasma. The initiative behind this trial was the available clinical experience of improved melasma coexisting with acne when the patients were treated with flutamide. There is theoretical evidence of potential association between melasma and other androgenic-related conditions such as acne, polycystic ovarian disease, and hirsutism. The mechanism behind the effect may lie in modifications on alpha-melanocytestimulating hormone or cyclic adenosine monophosphate-elevating agents affecting the melanin synthesis. The use of topical drugs is much more attractive for dermatologists because there is the potential for relatively mild systemic adverse effects during topical use of drugs. Topical flutamide would be safer compared to its oral form taking into account potentials for severe side effects when oral flutamide has been used [19]

To our knowledge there is no previous published data comparing between the efficacy of topical Flutamide $1 \%$ alone and incombination with Carboxytherapy in treatment of patients with melasma.

Carboxytherapy, regarding the patient satisfaction in the different studied groups, group B showed the highest satisfaction, 3 patients were extremely satisfied (20\%), 7 patients were very satisfied $(46.7 \%), 4$ patients were modertely satisfied (26.7\%) and 1 patient was mildly satisfied (6.7\%). Carboxy injection when added to topical Flutamide showed a highest patient satisfaction.

To our knowledge there is no previous published data on the use of carboxy injection in melasma treatment.

Carboxytherapy has been used earlier for treatment of dark under eye circles, stretch marks, cellulite, localized fat pads, alopecia and linear atrophic scars with promising results in human and animal studies. Considering some ambiguity in etiologic mechanisms of melasma, it is also very hard to understand the exact mechanism of action observed for the effect of carboxytherapy on melasma. The mechanism behind the effect may lie in the first effect of $\mathrm{CO} 2$ injection is a strong vasodilatation. The $\mathrm{CO}_{2}$ injected is recognized as an oxygen deficit and this causes an increase in blood flow and growth factors such as vascular endothelial growth factor (VEGF) that stimulates the production of new blood vessels. $\mathrm{CO} 2$ injection has a beneficial effect on cutaneous circulation and vasomotion and increases transcutaneous oxygen tension $\left(\mathrm{tc}-\mathrm{PO}_{2}\right)$. The increase of tc- $\mathrm{PO}_{2}$ may be related to an increase of capillary blood flow, induced by hypercapnia, and a reduction in cutaneous oxygen consumption, caused by the vasodilating effect of $\mathrm{CO}_{2}$, or it may also be explained as a right shift of the $\mathrm{O}_{2}$ dissociation curve (Bohr effect) [20]. The resolution of dark circles may be explained by the ability of $\mathrm{CO} 2$ to increase blood flow and improve the inflammatory state [21].

Regarding the side effects in the present study, they were more reported in group B while no side effects were reported in group A. In group B, there was burning pain and wheal at the site of injection in all patients (100\%) at the time of injection only that relieved rapidly after the session. In group A, no side effects were reported in all patients. 


\section{Conclusion:}

As new treatment for melasma topical flutamide was effective and safe therapeutic modalities. Carboxytherapy could be effective and safe new treatment modality for melasma as adjuvant treatment with topical flutamide.

\section{References}

1- HEXSEL D.M., LACERDA D.A., CAVALCANTE A.S., MACHADO FILHO C.A., KALIL C.L., AYRES E.L., et al.: Epidemiology of melasma in Brazilian patients: A multicenter study. Int. J. Dermatol., 53 (4): 440-4, 2014.

2- KUMAR S., MAHAJAN B.B. and KAMRA N.: Melasma in North Indians: A clinical, epidemiological, and etiological study. Pigment. Int. J., 1 (2): 95-9, 2014.

3- ADALATKHAH H. and SADEGHI-BAZARGANI H.: The first clinical experience on efficacy of topical flutamide on melasma compared with topical hydroquinone: A randomized clinical trial. Drug. Des. Devel. Ther., 9: 4219-25, 2015.

4- PINHEIRO N.M., CREMA V.O., MILLAN B.M., CARVALHO F.A. and MENDONÇA A.C.: Comparison of the effects of carboxytherapy and radiofrequency on skin rejuvenation. J. Cosmet. Laser. Ther., 17 (3): 156-61, 2015.

5- SARMA N. and JOYEETA C.: Clinical Features and Classification of Melasma, Wood's Lamp, and Melasma Area Severity Index Score. In. Sarkar R. Melasma: A Monograph. J.P. Medical. Publishers, p15, 2015.

6- FLEMING J. and SAQIB B.: Combination (5\% Hydroquinone, $0.1 \%$ Tretinoin and $1 \%$ Hydrocortisone) Cream in Treating Facial Hyperpigmentation: A Retrospective Patient Satisfaction Survey. JCDSA, 4 (5): 329-31, 2014.

7- AYRES E.L., COSTA A., JORGE AC.F., JÚNIOR J.E.G., SZRAJBMAN M. and SANT'ANNA B.: Monocentric prospective study for assessing the efficacy and tolerability of a cosmeceutical formulation in patients with melasma. Surg. Cosmet. Dermatol., 8 (3): 232-40, 2016.

8- PEREZ-BERNAL A, MUÑOZ-PÉREZ MA. and CAMACHO F.: Management of facial hyperpigmentation. Am. J. Clin. Dermatol., 1 (5): 261-8, 2000.

9- ACHAR A. and RATHI K.: Melasma: A clinico-epide- miological study of 312 cases. Indian. J. Dermatol., 56 (4): 380-2, 2011.

10- KANG W.H., YOON K.H., LEE E.S., KIM J., LEE K.B., YIM H., et al.: Melasma: Histopathological characteristics in 56 Korean patients. Br. J. Dermatol., 146 (2): 228-37, 2002.

11- ILKNUR T., BICAK M.Ü., DEMIRT A.M. and ÖZKAN Ş.: Glycolic acid peels versus amino fruit acid peels in the treatment of melasma. Dermatol. Surg., 36 (4): 4905,2010 .

12- RIGOPOULOS D., GREGORIOU S. and KATSAMBAS A.: Hyperpigmentation and melasma. J. Cosm. Dermatol., 6 (3): 195-202, 2007.

13- HANDEL A.C., MIOT L.D. and MIOT H.A.: Melasma: A clinical and epidemiological review. An. Bras. Dermatol., 89 (5): 771-82, 2014.

14- MOIN A.S., JABERY Z. and FALLAH N.S.: Prevalence and awareness of melasma during pregnancy. Int. J. Dermatol., 45 (3): 285-8, 2006.

15-HEXSEL D., RODRIGUES T.C. and DALFORNO: Melasma and pregnancy in southern Brazil. J. Eur. Acad. Dermatol. Venereol., 239 (3): 367-8, 2009.

16- SARVJOT V., SHARMA S., MISHRA S. and SINGH A.: Melasma: A clinicopathological study of 43 cases. Indian. J. Pathol. Microbiol., 52 (3): 357-9.

17- ELBULUK N. and GRIMES P.E.: What's in the Pipeline for Melasma and Vitiligo. Melasma and Vitiligo in Brown Skin. Springer. India., p 361-377, 2017.

18- ADALATKHAH H., POURFARZI F. and SADEGHIBAZARGANI H.: Flutamide versus a cyproterone acetateethinyl estradiol combination in moderate acne: A pilot randomized clinical trial. Clin. Cosmet. Investig. Dermatol., 4: 117-21, 2011.

19- BAGHERANI N.: Efficacy of topical flutamide in the treatment of melasma. J. Dermatolog. Ther., 29 (5): $297-$ 7, 2016.

20- VARLARO V., MANZO G., MUGNAINI F., BISACCI C., FIORUCCI P., DE RANGO P., et al.: Carboxytherapy: effects on microcirculation and its use in the treatment of severe lymphedema. Acta. Phlebol., 8: 1-13, 2007.

21- ZENKER S.: Carboxytherapy carbon dioxide injections in aesthetic medicine. J. Prime., 2 (1): 42-50, 2012. 


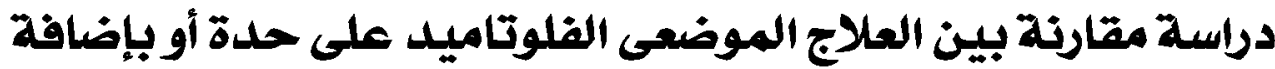

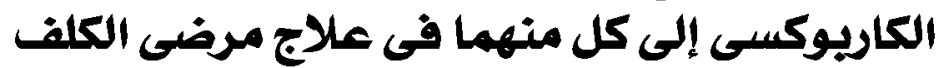

المقدمة: يعتبر الكلف واحد من أكثر أسباب زيادة تصبغ الوجه حيث تؤلى إلى مثاكل جمالية ونفسية. توجل ويسائل علاجية مختلفة للكلف لوفي ومع ذلك غالباً ما تكون مخيبة للآمال.

الهدف من الدراسـة: مقارنة بين فاعلية الفلوتاميد الموضعى ا٪ والكاربوكسى فى علاج مرضى الكلف.

المرضى وطرق البحث: أشتملت الدراسة على ثلاثين مريضة تعانى من الكلف، تم جمعهم منالعيادات الخارجية لقسم الجلدية والتناسلية

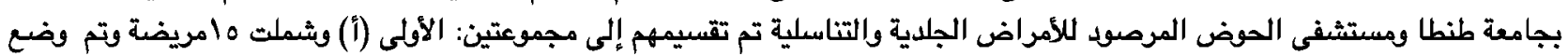

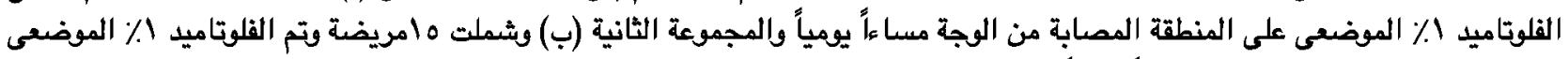

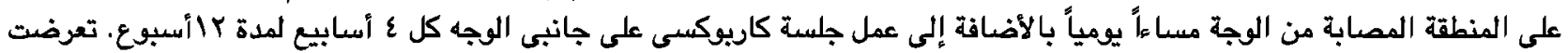

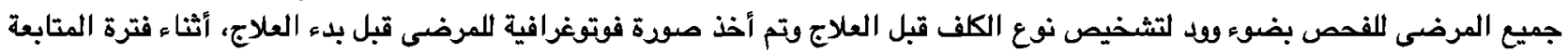

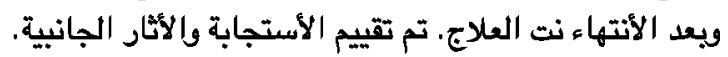

النتائج: أظهرت المجموعتان (أ، ب) تغيرات كبيرة جداً فى درجة معامل ماسى المعدل بعد إستخدام العلاج. المجموعة (ب) أظهرت الأعلى

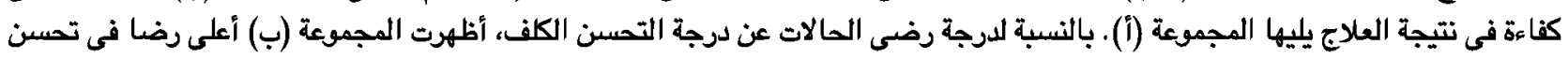
الكلف يليها المجموعة (أ). تم رصد أثار جانبية في المجموعة (ب) بينما لم يحدث أَى أثثار جانبية في المجموعة (أ). الإستتاج: الفلوتاميد الموضعى علاج جيد وفعال في حالات الكلف ويدوف حدوث أى آثار جانبية في علاج مرضى الكلف. حقن الكاربوكسى

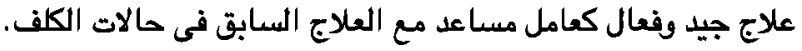

